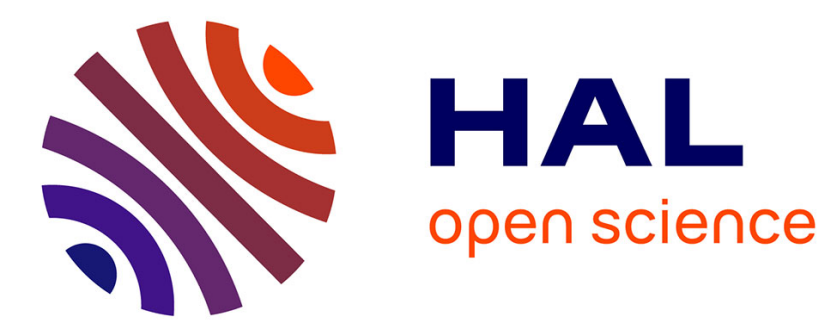

\title{
Generation of powerful organic electron donors by water-assisted decarboxylation of benzimidazolium carboxylates
}

\author{
Guillaume Tintori, Arona Fall, Nadhrata Assani, Yuxi Zhao, David
}

Bergé-Lefranc, Sébastien Redon, Patrice Vanelle, Julie Broggi Broggi

\section{To cite this version:}

Guillaume Tintori, Arona Fall, Nadhrata Assani, Yuxi Zhao, David Bergé-Lefranc, et al.. Generation of powerful organic electron donors by water-assisted decarboxylation of benzimidazolium carboxylates. Organic Chemistry Frontiers, 2021, 8 (6), pp.1197-1205. 10.1039/d0qo01488e . hal-03142833

\section{HAL Id: hal-03142833 \\ https://hal.science/hal-03142833}

Submitted on 16 Feb 2021

HAL is a multi-disciplinary open access archive for the deposit and dissemination of scientific research documents, whether they are published or not. The documents may come from teaching and research institutions in France or abroad, or from public or private research centers.
L'archive ouverte pluridisciplinaire $\mathbf{H A L}$, est destinée au dépôt et à la diffusion de documents scientifiques de niveau recherche, publiés ou non, émanant des établissements d'enseignement et de recherche français ou étrangers, des laboratoires publics ou privés. 


\section{Generation of powerful organic electron donors by water-assisted decarboxylation of benzimidazolium carboxylate.}

Received 00th January 20xx, Accepted 00th January 20xx

DOI: $10.1039 / x 0 x x 00000 x$

\author{
Guillaume Tintori, ${ }^{a}$ Arona Fall, ${ }^{a}$ Nadhrata Assani, ${ }^{a}$ Yuxi Zhao, ${ }^{\text {a }}$ David Bergé-Lefranc, ${ }^{b}$ Sébastien \\ Redon, ${ }^{a}$ Patrice Vanelle ${ }^{a}$ and Julie Broggi ${ }^{a}$.
}

\begin{abstract}
Organic Electron Donors (OEDs) are increasingly used as efficient reducing agents in various radical reactions. However, their sensitivity to air restraints their practical use and the development of further industrial applications. To meet the community's needs, this paper reports the preparation of air- and moisture-stable carboxylate precursors that can be conveniently activated into the corresponding organic reducer. The new strategy consists in the water-assisted decarboxylation of the adduct at room temperature, providing a straightforward protocol for the single-electron transfer reduction of aryl halides and sulfonamide. The resulting aryl radicals are engaged in the first examples of OED-promoted intermolecular addition reactions. A thorough mechanistic study supports the in-situ formation of the organic reducer.
\end{abstract}

\section{Introduction}

Reduction reactions promoted by electron transfer are now recognized as a powerful group-tolerant strategy for new elaborate reactions and rapid increase of molecular complexity. ${ }^{1}$ Long limited to toxic and highly aggressive metalbased reducing agents, reduction reactions are enjoying renewed interest since the development of metal ${ }^{2}$ or organic ${ }^{3}$ photocatalysts. Although used in stoichiometric amounts, ${ }^{4}$ readily-prepared enamine-based Organic Electron Donors $(\mathrm{OEDs})^{5}$ are also attracting attention as a serious alternative as shown by the growing number of useful applications (initiators for coupling reactions or polymerizations, redox switches and flow batteries, greenhouse gas reduction). ${ }^{6}$ They spontaneously promote single- (SET) or double electrontransfers (DET) to substrates that are thermodynamically too uphill for current SET-photoredox catalysts. At ground state, they generate radical or anionic intermediates from substrates with redox potential $E_{1 / 2}<-1.0 \mathrm{~V}^{7}$ UV-photoexcitation (365 $\mathrm{nm}$ ) of OEDs further enhances their reducing power to substrates with $E_{1 / 2}$ up to - $3.5 \mathrm{~V}^{8}$. Depending on their structures, the enamines are stable and can be stored and manipulated under inert atmosphere. ${ }^{5,9}$ In other cases, the dimeric form is elusive and decomposes after a few minutes or hours into the corresponding $\mathrm{N}$-heterocyclic carbene (NHC) (Scheme 1). ${ }^{9 a, 10}$ In addition to these short half-life issues, OEDs like any other strong reducing agents, are highly sensitive to oxygen. $^{11}$

\footnotetext{
Aix Marseille Univ, CNRS, Institut de Chimie Radicalaire ICR, Faculté de Pharmacie, 13005 Marseille, France. [julie.broggi@univ-amu.fr and patrice.vanelle@univ amu.fr]

${ }^{b .}$ Aix Marseille Univ, CNRS, IRD, Laboratoire IMBE UMR 7263, Faculté de Pharmacie, 13005 Marseille, France.

Electronic Supplementary Information (ESI) available: [details of any supplementary information available should be included here]. See
}

To overcome these constraints, processes consisting of the activation of air-stable precursors with strong bases ${ }^{10,12}$ or under high working temperatures ${ }^{13}$ have been used to in situ generate the reducer. However, strong bases present limited group tolerance and thermal activation $\left(150^{\circ} \mathrm{C}\right)$ impedes the use of volatile substrates or solvents. To significantly improve the practicality of OEDs, there is a need for air-stable precursors allowing the convenient in situ generation of enamine reducers under mild conditions.

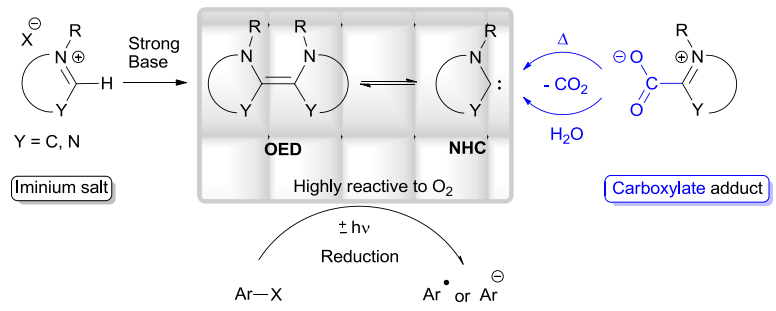

Scheme 1. OED formation through air-stable precursors.

This manuscript illustrates the synthesis and the activation of carboxylate and sulfinate iminium adducts into the corresponding organic reducer. The new strategy consists in the water-assisted decarboxylation (or desulfination) of the adduct at room temperature (Scheme 1). A thorough mechanistic study supports the in-situ formation of the enamine-type reducer. Their scope will also be discussed, notably for OED-promoted intermolecular radical addition reactions.

\section{Results and discussion}

Our study began by comparing the physico-chemical and activation parameters of various carboxylate and sulfinate adducts. Adapted from reported procedures, ${ }^{13,14,15}$ the adducts were prepared in a two-step procedure involving first 
deprotonation of the iminium salt, followed by trapping of the generated species with carbon dioxide or sulfur dioxide atmosphere (Scheme 2). All the precursors were obtained in moderate to good yields (51-98\%).

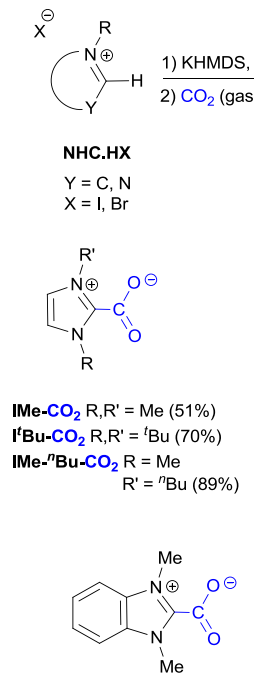

$\mathrm{Bz} \mid \mathrm{Me}-\mathrm{CO}_{2}(90 \%)$

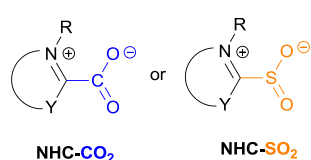

$\begin{array}{lr}\mathrm{NHC}-\mathrm{CO}_{2} & \mathrm{NHC}-\mathrm{SO}_{2} \\ 51-90 \% & 90-98 \%\end{array}$

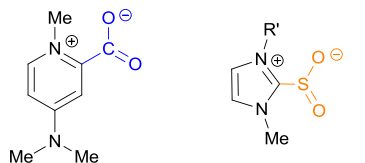

DMAP-Me- $\mathrm{CO}_{2}(70 \%) \quad$ IMe-Et-SO $\mathrm{R}^{\prime}=\mathrm{Et}(90 \%)$ IMe $-{ }^{n} \mathrm{Bu}-\mathrm{SO}_{2} \mathrm{R}^{\prime}={ }^{n} \mathrm{Bu}(98 \%)$

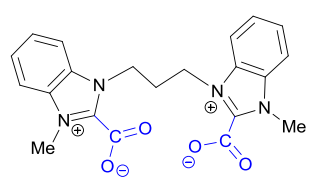

Bis-BzIMe- $-\mathrm{CO}_{2}(90 \%)$
Scheme 2. Synthesis of carboxylate and sulfinate adducts.

While expecting easier cleavage of the $\mathrm{SO}_{2}$ moiety than the $\mathrm{CO}_{2}{ }^{16}$ thermogravimetric analysis (TGA) at the solid states of these adducts surprisingly indicated that the sulfinate adducts would decompose at higher temperatures than their carboxylate counterparts (IMe- ${ }^{n} \mathrm{Bu}-\mathrm{SO}_{2}, 190^{\circ} \mathrm{C}$ vs. IMe- ${ }^{n} \mathrm{Bu}-$ $\mathrm{CO}_{2}, 141^{\circ} \mathrm{C}$ ) (Table 1). However, this physical feature directly contrasted with their instability in air (leading to the formation of hydrogen sulfite salt IMe-R'. $\mathrm{HHSO}_{3}$ ) and with their higher reactivity in solution under thermal activation (See supporting information (S.I.), Scheme S1 and Table S2). ${ }^{17}$

In $\mathrm{NHC}-\mathrm{CO}_{2}$ series, the presence of bulkier $\mathrm{N}$-groups around the carboxylate moiety facilitates the decarboxylation (Table $1, \mathbf{I M e}^{-\mathrm{CO}_{2}} 140^{\circ} \mathrm{C}$ vs. $\mathrm{I}^{\mathrm{t}} \mathrm{Bu}-\mathrm{CO}_{2} 63^{\circ} \mathrm{C}$ ). ${ }^{18,19 \mathrm{C}}$ At $150^{\circ} \mathrm{C}$, these carboxylate adducts can be decarboxylated to generate an organic reducing species. ${ }^{13}$ Nevertheless, the steric hindrance induce by the tert-butyl groups may also impede the efficient formation of the active dimeric OED-form. To balance ease of decarboxylation and dimerization, we prepared IMe${ }^{n} \mathrm{Bu}-\mathrm{CO}_{2}$ bearing a longer $\mathrm{N}$-butyl chain. However, the decarboxylation temperature of IMe- ${ }^{n} \mathrm{Bu}-\mathrm{CO}_{2}$ was not affected by this slight increase in hindrance, displaying a similar value $\left(141^{\circ} \mathrm{C}\right)$ to that of $\mathrm{IMe}^{-\mathrm{CO}_{2}}$. Encouragingly, the 1,3dimethylbenzimidazolium adduct BzIMe- $\mathrm{CO}_{2}$ showed a low decarboxylation temperature $\left(52^{\circ} \mathrm{C}\right)$ and a relative stability of the generated species until its decomposition at $119^{\circ} \mathrm{C}$ Despite a first decarboxylation at low temperature $\left(50^{\circ} \mathrm{C}\right)$, the loss of the second molecule of $\mathrm{CO}_{2}$ of the $N, N^{\prime}$-bridged bisbenzimidazolium carboxylate adduct Bis-BzIMe- $\mathrm{CO}_{2}$ was not clearly observed before its decomposition at $219^{\circ} \mathrm{C}$ (S.I., Figure S2).

The lower IR frequency of the carbonyl asymmetric stretching $\left(1632 \mathrm{~cm}^{-1}\right)$ of BzIMe- $\mathrm{CO}_{2}$ was also in line with the low frequencies usually observed for adducts more prone to decarboxylation, such as I $^{t} \mathbf{B u}-\mathbf{C O}_{\mathbf{2}}\left(1609 \mathrm{~cm}^{-1}\right)$ (Table 1). ${ }^{13,18}$ More thermally stable imidazolium adducts $\mathbf{I M e}-\mathrm{CO}_{2}$ and IMe${ }^{n} \mathrm{Bu}_{-} \mathrm{CO}_{2}$ displayed higher values $\left(1645\right.$ and $1657 \mathrm{~cm}^{-1}$, respectively). UV-Vis spectroscopy indicated similar maximum absorption wavelengths (269-277 $\mathrm{nm}$ ) for all imidazolium and benzimidazolium adducts (Table 1 ).

Table 1. Physical features of NHC- $\mathrm{CO}_{2}$ and NHC-SO

\begin{tabular}{|c|c|c|c|}
\hline Precursor & $\mathrm{T}-\mathrm{CO}_{2}$ or $-\mathrm{SO}_{2}\left[{ }^{\circ} \mathrm{C}\right]^{a}$ & $v_{\text {COasym }}\left[\mathrm{cm}^{-1}\right]^{a}$ & $\lambda_{\max }[\mathrm{nm}]$ \\
\hline IMe- ${ }^{n} \mathrm{Bu}-\mathrm{SO}_{2}$ & 190 & - & 274 \\
\hline DMAP-Me- $\mathrm{CO}_{2}$ & 181 & 1624 & 288 \\
\hline IMe-Et-SO & 160 & - & 274 \\
\hline IMe- ${ }^{n} \mathrm{Bu}-\mathrm{CO}_{2}$ & 141 & 1657 & 274 \\
\hline $\mathrm{IMe}^{-\mathrm{CO}_{2}}$ & 140 & 1645 & 273 \\
\hline $\mathrm{I}^{t} \mathrm{Bu}-\mathrm{CO}_{2}$ & 63,115 & 1609 & 269 \\
\hline BzIMe-CO & 52,119 & 1632 & 270,277 \\
\hline Bis-BzIMe- $\mathrm{CO}_{2}$ & 50,219 & 1669 & 272,277 \\
\hline
\end{tabular}

We then evaluated the stability of our carboxylate and sulfinate adducts towards water. Indeed, Louie and Falvey showed that the decarboxylation can be facilitated by the presence of water in an organic solvent. ${ }^{18,19}$ While stable in pure water or stored at air, $\mathrm{N}$-alkyl $\mathbf{N H C}-\mathrm{CO}_{2}$ adducts were rapidly decarboxylated when dissolved in an water/organic solvent mixture, yielding the corresponding carbonate salt $\mathrm{NHC} \mathrm{HHCO}_{3}$ upon fast protonation of the carbene intermediate (Scheme 3). ${ }^{18,19}$ Fast decarboxylation in a $5 \%$ $\mathrm{H}_{2} \mathrm{O}$ /dioxane mixture and formation of corresponding carbonate salts were indeed observed by ${ }^{1} \mathrm{H}$ NMR for our imidazolium and benzimidazolium $\mathrm{NHC}-\mathrm{CO}_{2}$ series. Sulfinate adducts $\mathbf{N H C}-\mathrm{SO}_{2}$ also quickly decomposed, since exposure to air moisture was enough to induce the $\mathrm{SO}_{2}$ cleavage, leading to the corresponding hydrogen sulfite salts (S.I., Scheme S1). Like with $\mathrm{N}$-aryl $\mathrm{NHC}-\mathrm{CO}_{2},{ }^{18}$ water was only hydrogen-bonded to the $\mathrm{CO}_{2}$ moiety of the aminopyridinium carboxylate adduct DMAP-Me- $\mathrm{CO}_{2}$, and did not trigger its decarboxylation (Scheme 3). ${ }^{13}$

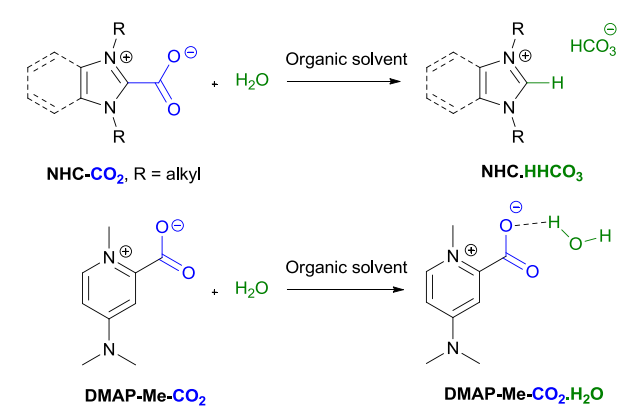

Scheme 3. Water activation of carboxylate adducts.

The same decarboxylation strategy was then performed in the presence of the substrate to reduce (1-iodo-2-(3phenoxypropylbenzene) 1a) (Table 2). 4 equivalents of precursors were used to in situ generate 2 equivalents of the dimeric OED form. While activation of $\mathbf{I M e}-\mathrm{CO}_{2}$ required a high 
temperature of $150^{\circ} \mathrm{C}$ under previous strategy (Entries 1-2), ${ }^{13}$ addition of $5 \%$ of degassed water (35 equiv.) led to its decarboxylation at room temperature and to the partial reduction of 1a (60\%) under UV-irradiations (Entry 5). ${ }^{20}$

As predicted above, the introduction of a longer $N$-alkyl chain did not ease the activation of the precursor. Compared to IMe$\mathbf{C O}_{2}$, water activation of $\mathbf{I M e}-{ }^{n} \mathbf{B u}-\mathbf{C O}_{2}$ led to the same reduction of 1a (Entry 6, 60\%). On the other hand, the higher steric hindrance of ${ }^{t} \mathrm{Bu}-\mathrm{CO}_{2}$ facilitated the decarboxylation, providing a slight higher reduction rate (Entry 7, 69\%). ${ }^{21}$ As expected from the weakness of the longer $\mathrm{C}-\mathrm{SO}_{2}$ bond, the sulfinate adducts $\mathbf{I M e}-\mathbf{E t}-\mathrm{SO}_{2}$ and $\mathbf{I M e}-{ }^{{ }^{n}} \mathrm{Bu}_{-} \mathrm{SO}_{2}$ performed better than their carboxylate counterparts under thermal activation (S.I., Table S2, entries 10-11, 99 and 69\% respectively at $120^{\circ} \mathrm{C}$ versus $6 \%$ for $I M e-\mathrm{CO}_{2}$ ) (underlying the easier loss of the $\mathrm{SO}_{2}$ moiety). Nevertheless, the low reducing reactivity observed upon water activation (Table 2, Entries 8-9, 16 and 14\%) and their poor stability at air storage clearly disqualified them as convenient OED-precursors.

As anticipated from our stability study, hydrogen-bonding of water to the aminopyridinium carboxylate DMAP-Me- $\mathrm{CO}_{2}$ was not sufficient to induce an efficient decarboxylation, leading only to traces of reduction product (Entry 10,6\%). In line with the TGA and IR conclusions, the benzimidazolium precursor BzIMe- $\mathrm{CO}_{2}$ offered the best reactivity, with $80 \%$ reduction at room temperature (Entry 11). The $N, N^{\prime}-$ trimethylene-bridged derivative Bis-BzIMe- $\mathrm{CO}_{2}$ might have induced faster formation of the dimeric reducing agent, $N, N^{\prime}$ bridged dibenzimidazolin-2-ylidene DiBzlMe. However, its lower reactivity (Entry 12, 27\%) was consistent with the sluggish second decarboxylation process predicted by TGA.

Evaluation of the influence of water showed that a decrease or an increase over the range of $1.5-10 \% \mathrm{H}_{2} \mathrm{O}$ slightly decreased the reduction rate (Entries 11, 14-16). As expected, absence of water was deleterious for the formation of the active reducing species (Entry 13, 61\%). These fluctuations highlight the impact of the first activation step on the reaction outcome. Efficient decarboxylation of the precursor required $5 \%$ concentration of water in DMF. This $5 \% \mathrm{H}_{2} \mathrm{O}$ concentration also provided fast decomposition rates of $\mathbf{I M e}-\mathrm{CO}_{2}$ in Falvey's study. ${ }^{19}$ Likewise, a trend towards faster decomposition was observed with decreasing solvent polarity (Entries 11, 17-19). Non-polar solvents decrease the dipole moment, destabilizing the zwitterionic adduct and easing the release of $\mathrm{CO}_{2} \cdot{ }^{19}$ The best reduction reactivities were observed with less polar THF and 1,4-dioxane (Entries 18-19, 90 and 99\%) compared to polar DMF and $\mathrm{CH}_{3} \mathrm{CN}$ (Entries 11 and 17, 80 and 68\%). This decrease in solvent polarity did not seem to be detrimental to the second step of electron-transfer. In these optimized $5 \%$ $\mathrm{H}_{2} \mathrm{O} / 1$,4-dioxane conditions, the precursor BzIMe- $\mathrm{CO}_{2}$ was thus the best candidate, giving a high yield of the reduced product 2a (Entry 19, 90\%). The OED-precursor BzIMe- $\mathrm{CO}_{2}$ was still active after several months of storage in air.

Several experiments were then performed to elucidate the mechanism behind this reduction process and confirm the formation of dimeric OEDs upon water activation of the carboxylate adduct (Table 3). First, evidence supporting an electron transfer mechanism was obtained through the addition of commonly used inhibitors. The reduction of 1a was drastically diminished in the presence of inhibitors such as the radical trap TEMPO (2,2,6,6-tetramethyl-1-piperidinyloxy) $(40 \%)$, oxygen $(44 \%)$ or the competitive electron acceptor $p$ DNB (para-dinitrobenzene) (0\%) (Entries 2-4).

Table 2. Optimization of the reduction process.

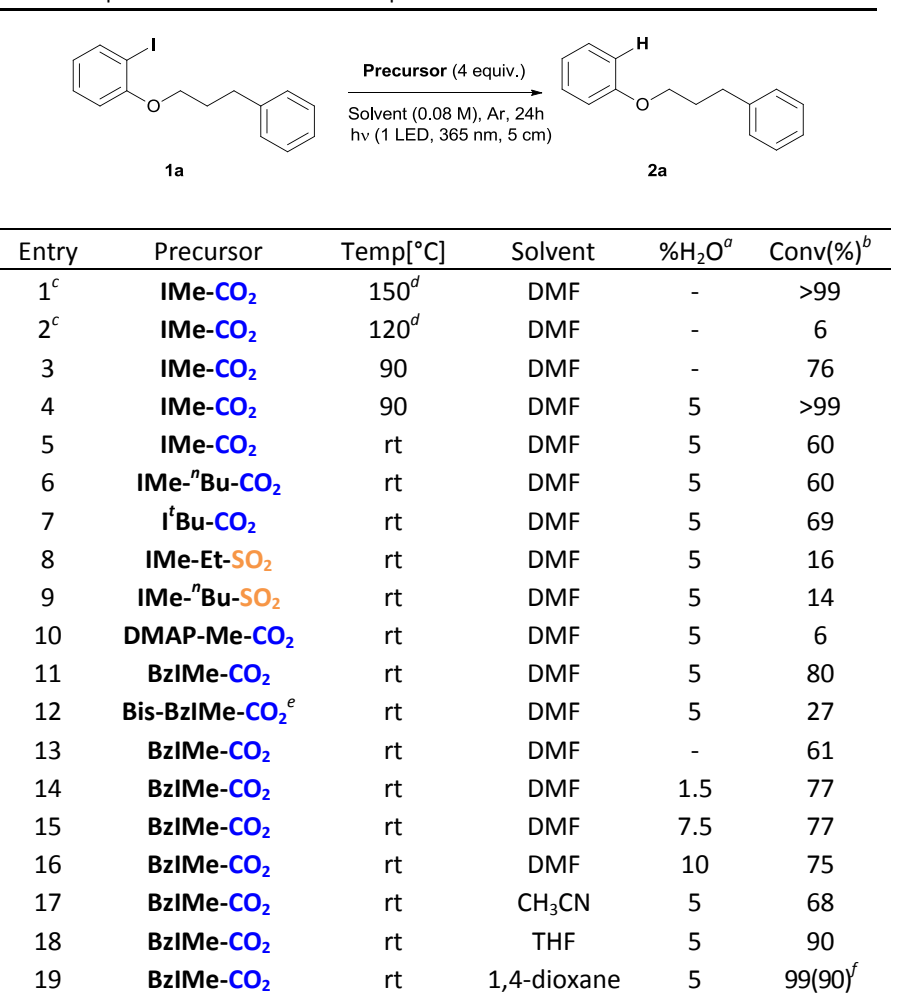

${ }^{a}$ Degassed water. ${ }^{b}$ Conversion determined by ${ }^{1} \mathrm{H}$ NMR analysis. ${ }^{\mathrm{c}}$ Data excerpted from Ref. $13 .{ }^{d}$ Without $h v .{ }^{e} 2$ equiv. ${ }^{f}$ Yield.

To gain insights into the active reducing species at work in this process, we first compared the reduction of $1 \mathrm{a}$, directly using the active reducer di-1,3-dimethylbenzimidazolin-2ylidene DiBzIMe $\left(E_{1 / 2}(D M F)=-0.88 \mathrm{~V} v\right.$ s. SCE) or the precursor form BzIMe- $\mathrm{CO}_{2}$. With both electron sources, reduction of iodoarene 1a required UV-irradiations to proceed (Table 3, Entries 1,7 vs. 5,8). ${ }^{22}$ This is not surprising, as dibenzimidazolinylidene-type OEDs, such as DiBzIMe, are SETreducers $\left(E_{1 / 2} \approx-0.8 \mathrm{~V} v\right.$ s. SCE) only able to reduce aryl iodide under high temperatures $\left(>100^{\circ} \mathrm{C}\right)$ or UV-photoexcitation $(\lambda=$ $365 \mathrm{~nm})$. $5,12 \mathrm{a}$

Although the contribution of water was unquestionable (Table 3, Entry 1 vs. 6), note that UV-irradiations alone could also participate to the decarboxylation step of $\mathbf{N H C}-\mathrm{CO}_{2}$ precursors (Table 2, Entry 3 and Table 3, Entry 6). Compared to thermal activation, 1a was reduced at drastically lower temperatures $\left(90^{\circ} \mathrm{C}\right.$ with $\mathbf{I M e}-\mathrm{CO}_{2}, 30^{\circ} \mathrm{C}$ with $\left.\mathrm{BzIMe}-\mathrm{CO}_{2}\right)$ albeit at lower conversion rates (76 and $64 \%$, respectively). Our UVLED light source emits at a wavelength $(\lambda=365 \pm 5 \mathrm{~nm}$ ) out of the range of wavelengths absorbed by $\mathrm{NHC}^{-\mathrm{CO}_{2}}(224-330 \mathrm{~nm}$, Table 1). Hence, rather than a photoexcitation of the 
carboxylate adducts, we attribute this activation of $\mathbf{I M e}-\mathrm{CO}_{2}$ and BzIMe- $\mathrm{CO}_{2}$ to localized temperature rises induced by UV radiations, assisting the elimination of $\mathrm{CO}_{2}$ and drastically decreasing the need for external heating. The slight increase of media temperature $\left(+5^{\circ} \mathrm{C}\right.$ at r.t) under UV-irradiations plus the polarity effect of the dioxane, that destabilizes the zwitterionic adduct, might be sufficient to slowly activate the decarboxylation of $\mathrm{BzIMe}-\mathrm{CO}_{2}\left(\mathrm{~T}-\mathrm{CO}_{2}=52^{\circ} \mathrm{C}\right.$ by TGA of the solid state, Table 1).

Table 3. Mechanistic study.

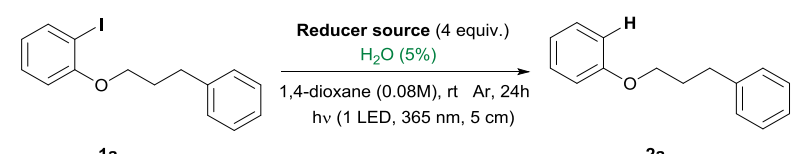

\begin{tabular}{cccc}
\hline Entry & Reducer source & $\begin{array}{c}\text { Changes to the standard } \\
\text { conditions }\end{array}$ & Conv (\%) ${ }^{a}$ \\
\hline 1 & BzIMe-CO $_{2}$ & - & 99 \\
2 & BzIMe-CO $_{2}$ & + TEMPO (4 equiv.) & 40 \\
3 & BzIMe-CO $_{2}$ & $+p$-DNB (4 equiv.) & 0 \\
4 & BzIMe-CO $_{2}$ & $+\mathrm{O}_{2}(1$ atm) & 44 \\
5 & BzIMe-CO $_{2}$ & no $h v$ & 0 \\
6 & BzIMe-CO $_{2}$ & no $\mathrm{H}_{2} \mathrm{O}$ & 64 \\
7 & DiBzIMe $^{b}$ & - & $>99$ \\
8 & DiBzIMe & \\
9 & BzIMeO (4) $^{b}$ & no $h v$ & 0 \\
10 & DMAP-Me-CO $_{2}$ & - & 0 \\
11 & - & no $\mathrm{H}_{2} \mathrm{O}$ & 12 \\
${ }^{a}$ Conversion determined by ${ }^{1} \mathrm{H}$ NMR analysis. ${ }^{b} 2$ equiv. & 10 \\
\hline
\end{tabular}

Table 4. Final benzimidazolium derivatives present in the organic and aqueous phases.

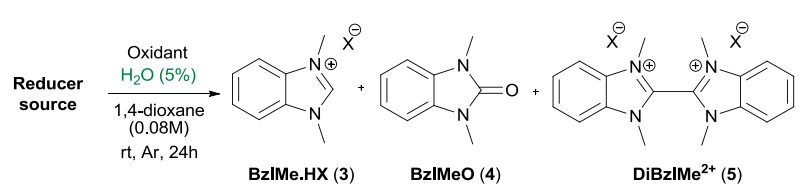

\begin{tabular}{|c|c|c|c|c|c|c|}
\hline \multirow[t]{2}{*}{ Entry } & \multirow{2}{*}{$\begin{array}{l}\text { Reducer } \\
\text { source }\end{array}$} & \multirow[t]{2}{*}{ Oxidant } & \multirow{2}{*}{$\begin{array}{l}\text { Changes to } \\
\text { the standard } \\
\text { conditions }\end{array}$} & \multicolumn{3}{|c|}{$\begin{array}{c}\text { Benzimidazolium } \\
\text { derivatives }^{a}\end{array}$} \\
\hline & & & & 3 & 4 & 5 \\
\hline 1 & BzIMe-CO & $\mathrm{C}_{2} \mathrm{Cl}_{6}$ & - & $\checkmark$ & $\checkmark$ & $x$ \\
\hline 2 & BzIMe-CO & $1 a$ & $+h v$ & $\checkmark$ & $\checkmark$ & $x$ \\
\hline 3 & DiBzIMe & $1 a$ & $+h v$ & $\checkmark$ & $\checkmark$ & $x$ \\
\hline 4 & DiBzIMe & $\mathrm{O}_{2}$ & no $\mathrm{H}_{2} \mathrm{O}$ & $x$ & $\checkmark$ & $x$ \\
\hline 5 & DiBzIMe & $\mathrm{C}_{2} \mathrm{Cl}_{6}$ & no $\mathrm{H}_{2} \mathrm{O}$ & $x$ & $\mathbf{x}$ & $\checkmark$ \\
\hline 6 & DiBzIMe & $\mathrm{C}_{2} \mathrm{Cl}_{6}$ & no $\mathrm{H}_{2} \mathrm{O},+h v$ & $\checkmark$ & $x$ & $\checkmark$ \\
\hline
\end{tabular}

${ }^{a}$ Observed by ${ }^{1} \mathrm{H}$ NMR. hv (1 LED, $\left.365 \mathrm{~nm}, 5 \mathrm{~cm}\right)$.

We also compared the benzimidazolium derivatives present at the end of reduction reactions (Table 4). According to the experiment, three derivatives could be retrieved: the 1,3-dimethylbenzimidazolium salt BzIMe.HX (3), the 1,3dimethylbenzimidazolin-2-one BzIMeO (4) or the tetramethyl-

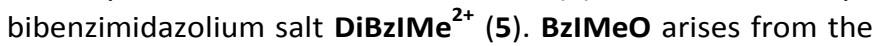
autoxidation of DiBzIMe (Entry 4$)^{23}$ and DiBzIMe ${ }^{2+}$ is the characteristic DET-oxidized form of DiBzIMe (Entry 5). ${ }^{5,24}$ The benzimidazolium salt BzIMe.HX can arise either from the protonation of 1,3-dimethylbenzimidazolin-2-ylidene carbene BzIMe or from the reaction of DiBzIMe with electrophiles, DiBzIMe ${ }^{*+}$ with $\mathrm{H}^{\cdot}$, or DiBzIMe ${ }^{2+}(\mathbf{5})$ with bases. ${ }^{24}$ Interestingly, reduction of 1a using either BzIMe- $\mathbf{C O}_{2}$ or DiBzIMe led in both cases to the recovery of largely $\mathbf{3}$ and traces of $\mathbf{4}$, but no trace of 5 (Entries 2-3). The absence of DiBzIMe ${ }^{2+}$ was explained by the instability of the radical cation DiBzIMe ${ }^{\bullet+}$ under UVirradiations (S.I., Scheme S3-S4). As matter of fact, EToxidation of DiBzIMe with $\mathrm{C}_{2} \mathrm{Cl}_{6}$ as strong oxidant gave a $1 / 1$ mixture of 3 and 5 under UV-irradiations (Entry 6 vs. 5). Hydrogen atom transfer (HAT) to radical cation DiBzIMe ${ }^{\cdot+}$ would lead to the unstable adduct $\mathrm{DiBz}_{\mathrm{IMeH}}^{+}$, which dissociates into salt $\mathbf{3}$ and carbene BzIMe (Scheme 5). ${ }^{24}$ Such unstable $\mathrm{DiBzIMeH}^{+}$can also be obtained upon reaction of DiBzIMe ${ }^{2+}$ with DiBzIMe. ${ }^{25,26}$

It could be argue that under UV-irradiations the carbene 1,3-dimethylbenzimidazolin-2-ylidene (BzIMe) itself could promote the single electron-transfer reduction of iodoarene 1a. Benzimidazolium salt $\mathbf{3}$ would also be the resulting oxidized species (Scheme 4). $\mathrm{N}$-heterocyclic carbenes are theoretically able to donate an electron, even though they have very low reducing powers (e.g. for the 1,3-bis(2,4,6trimethylphenyl)imidazolin-2-ylidene (IMes): $\mathrm{E}_{1 / 2}(\mathrm{DMF})=-0.20$ $\mathrm{V}$ vs. SCE). ${ }^{27}$ In the case of the ${ }^{t} \mathrm{Bu}-\mathrm{CO}_{2}$ precursor, the ${ }^{t} \mathrm{Bu}$ carbene could indeed be the electron donor species considering its sterically disfavoured dimerization (Table 2, Entry 7). ${ }^{21}$ Nonetheless, with BzIMe- $\mathrm{CO}_{2}$ as precursor, the halflife of the BzIMe carbene ought to be very short. The inclination of $N, N^{\prime}$-dimethylbenzimidazolium salts to rapidly and tightly dimerize upon deprotonation is well reported. ${ }^{28}$ Lemal briefly observed trace of BzIMe through dissociation of DiBzIMe at high temperature $\left(140^{\circ} \mathrm{C}\right)$, but the signal rapidly disappeared upon cooling. ${ }^{28 a}$ This demonstrates the high stability of DiBzIMe and the reversibility of the process. In our case, both thermal decarboxylation of $\mathbf{B z I M e C O}_{2}$ (S.I., Scheme S5) and deprotonation of BzIMe.HI salt (S.I., Scheme S2) allowed fast formation of the dimer species DiBzIMe. Monitoring of the decarboxylation of BzIMe- $\mathrm{CO}_{2}$ by ${ }^{1} \mathrm{H}$ and ${ }^{13} \mathrm{C}$ NMR at $70^{\circ} \mathrm{C}$ in $\mathrm{C}_{6} \mathrm{D}_{6}$ detected the formation of DiBzIMe but no trace of carbene BzIMe, even after several days of heating (Scheme 5). Moreover, when the reaction was performed with one equivalent of carboxylate $\mathrm{BzIMe}-\mathrm{CO}_{2}$, only $63 \%$ reduction was observed, consistent with in situ generation of 0.5 equivalent of the reducing dimeric form DiBzIMe (the remaining $13 \%$ accounted for direct homolytic cleavage of 1a under UV-irradiations, Table 3, Entry 11). 


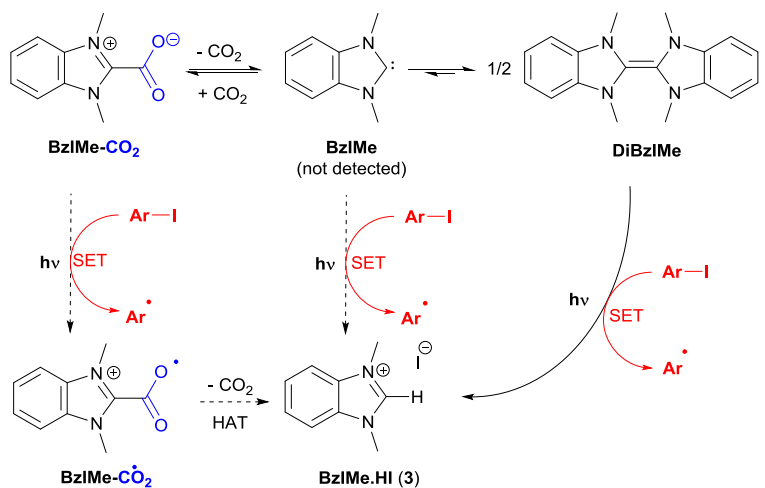

Scheme 4. Candidate pathways using benzimidazolium carboxylate for the ET-reduction of iodoarenes.

The contribution of the carboxylate form as active donor species was also considered. Direct photoexcited SET from BzIMe- $\mathrm{CO}_{2}$ to $1 \mathrm{a}$ would generate the corresponding aryl radical

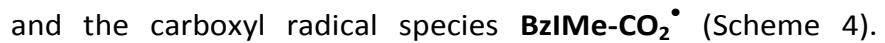
BzIMe- $\mathrm{CO}_{2}{ }^{\circ}$ would decompose into salt $\mathbf{3}$ upon decarboxylation and HAT. In fact, carboxylate derivatives are known as reducers able to promote photoinduced electron transfer to very strong acceptors (Ir* and $\mathrm{Ru}^{*}$ complexes or organic dyes). ${ }^{29}$ An electron-rich amino group near the carboxylate moiety is necessary to assist the electron transfer and the decarboxylation process. However, in our case, the electron-poor iminium moiety of BzIMe- $\mathrm{CO}_{2}$ should suffice to strongly disfavour any electron transfer from the carboxylate group to a poor acceptor like an iodoarene. The lack of reactivity of the aminopyridinium carboxylate DMAP-Me- $\mathrm{CO}_{2}$ (Table 3, Entry 10), presenting no sign of decarboxylation under these conditions, also makes it reasonable to conclude that the carboxylate form is not the active reducing species.

All these arguments suggest that the in situ generation of DiBzIMe proceeds according to the following mechanism (Scheme 5): Water-assisted decarboxylation of BzIMe- $\mathrm{CO}_{2}$ leads to the formation of the 1,3-dimethylbenzimidazolin-2ylidene BzIMe, which is protonated into benzimidazolium salt
3. Falvey showed that these two steps were stepwise and not concerted. ${ }^{19}$ A second molecule of BzIMe is added to salt $\mathbf{3}$ to form the cation intermediate $\mathbf{D i B z I M e H}{ }^{+}$. Rapid deprotonation of $\mathrm{DiBzIMeH}^{+}$with BzIMe leads to the formation of the active

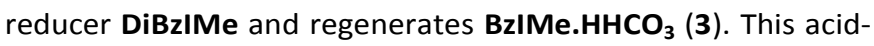
catalysed dimerization of BzIMe, where $\mathbf{3}$ is the acid, allows a complete shift of the Wanzlick enamine/carbene equilibrium toward the dimer form DiBzIMe. ${ }^{30}$ Small amounts of DiBzIMe could also come from the thermal decarboxylation of BzIMe$\mathrm{CO}_{2}$ under the UV-irradiation conditions. ${ }^{20}$ Photo-excited DiBzIMe then transfers a single electron to the iodoarene Arl, leading to the corresponding aryl radical $\mathbf{A r}^{\bullet}$ and the radical cation DiBzIMe ${ }^{\bullet+}$. The aryl radical $\mathbf{A r}^{\bullet}$ abstracts a hydrogen from the 1,4-dioxane to generate the final reduced compound. Disproportionation or HAT of the radical cation leads to the formation of the unstable cation $\mathrm{DiBz} \mathrm{MeH}^{+}$which decomposes into salt $\mathbf{3}$ and carbene BzIMe. The generated carbene can in turn form $\mathbf{3}$ after protonation.

To further investigate the scope of this water-activated OED-precursor, we examined the reduction of various aryl substrates, and their subsequent intramolecular and intermolecular radical addition on alkenes. Water activation of BzIMe- $\mathrm{CO}_{2}$ and UV-excitation of the as-formed DiBzIMe promoted the SET-reduction of various iodide and sulfonamide arenes 1a-j in moderate to excellent yields (Scheme 6). Exclusive formation of reduced products $\mathbf{2 b}$ and $\mathbf{2 c}$ (i.e. with no trace of the cyclised derivatives obtained by DET, S.I., Table S3) was in line with the SET capacities of DiBzIMe. ${ }^{12 a}$ The reducing system was tolerant to different functional groups including ester (2b, $\mathbf{2 c}$ and $\mathbf{2 d}$ ), ketone (2e) or cyano groups (2f), characteristic of the chemo-selectivity of OEDs. Bromoarenes with more negative reduction potentials were also partially reduced (2a, $\mathrm{Y}=\mathrm{Br}$ and $\mathbf{2 f}$ ). These highly challenging reduction reactions prove that the potency of DiBzIMe was maintained after in situ generation from BzIMe$\mathrm{CO}_{2}$. 


\section{ARTICLE}

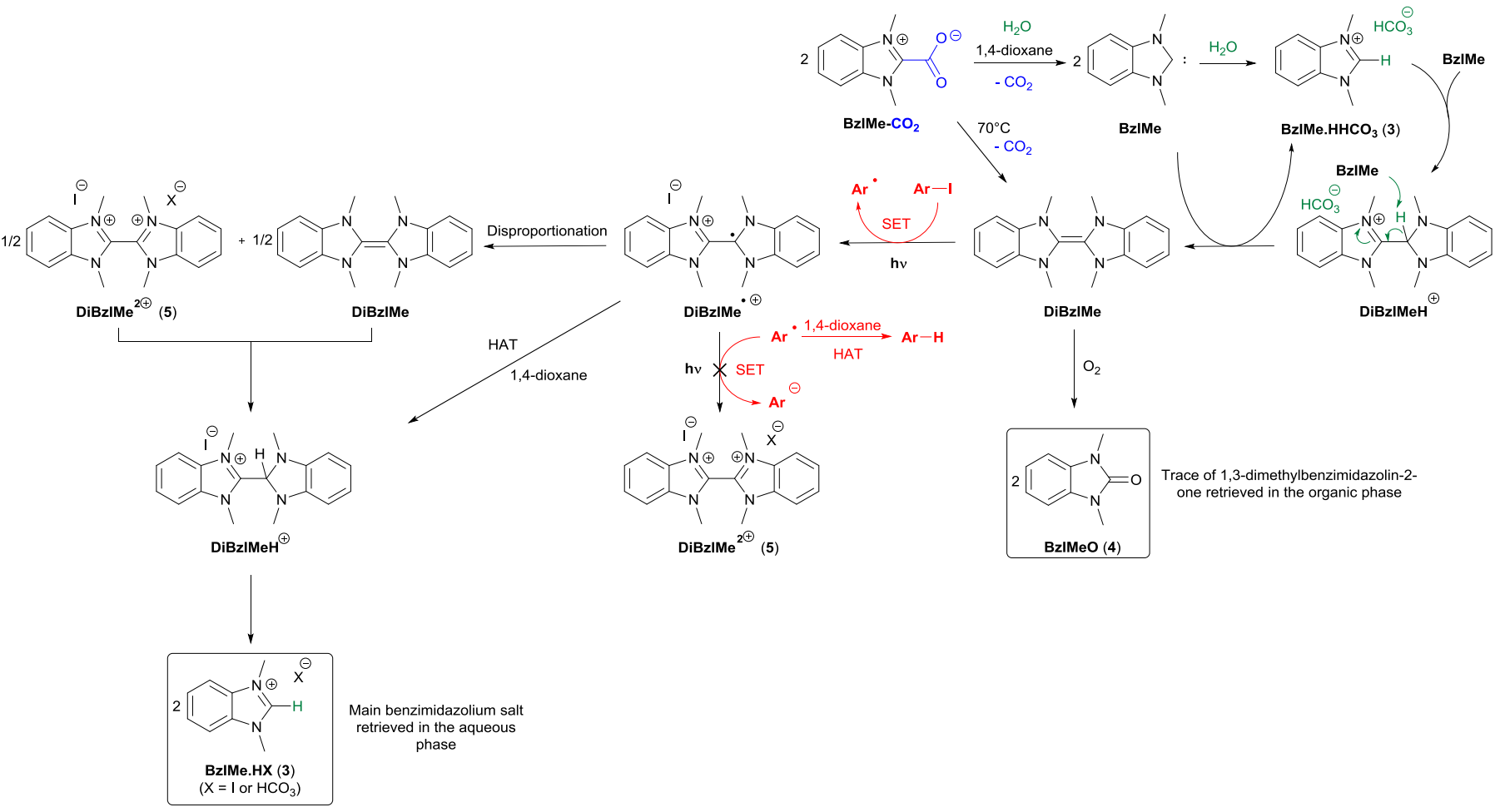

DMF was sometimes used when the reduction was slow to enhance the electron transfer. The moderate yields obtained for $\mathbf{2} \mathbf{g}$ and $\mathbf{2} \mathbf{i}$ can be attributed to a partial loss of these volatile reduced products during the work-up. Unfortunately, as previously observed with OED, presence of an alcohol group in $2 \mathbf{j}$ prevented the reduction reaction.
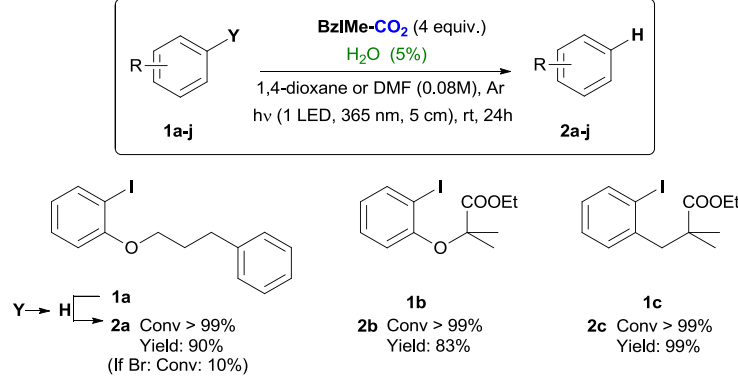

$$
1 \mathrm{~b}
$$

2b Conv $>99 \%$ Yield: $83 \%$ Conv $>99 \%$
Yield: $99 \%$
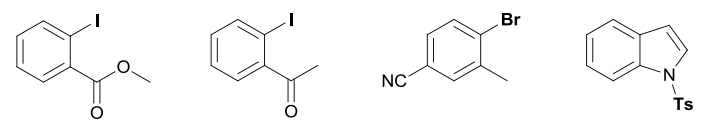

$1 d$

2d Conv $>99 \%$ $1 \mathrm{e}$ Conv $>99 \%$

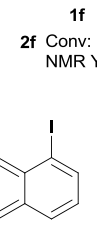

$1 \mathrm{f}$ Yield: $95 \%$ Conv: $17 \%$

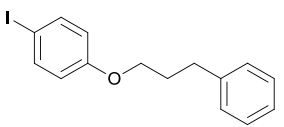

$1 \mathrm{~h}$

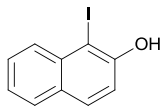

2a Conv $>99 \%$

2i Conv $>99 \%$
Yield: $42 \%$

1 2j Conv: $0 \%$ 
The aryl radicals obtained through reduction of the $\mathrm{Csp}^{2}-1$ bond were further engaged in intramolecular additions on alkenes via a 5-exo-trig cyclisation reaction, leading to the 2,3dihydrobenzofuran products $\mathbf{7}$ and $\mathbf{1 0}$ (Scheme 7). Formation of $\mathbf{8}$ arose from a recombination between the cyclized radical and traces of iodide radical generated upon UV-induced homolytic cleavage of the C-I bonds in 6 (Table 3, Entry 11, blank reaction). The cyclized radical obtained from 9 could either abstract a hydrogen to give $\mathbf{1 0}$ or disproportionate to give 11. ${ }^{31}$ Starting materials $\mathbf{6}$ and $\mathbf{9}$ accounted for the mass balance.
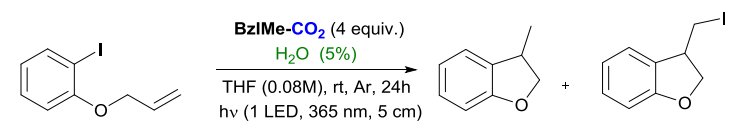

6

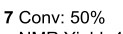
$\begin{array}{ll}7 \text { Conv: } 50 \% & 8 \text { Conv: } 10 \% \\ \text { NMR Yield: } 43 \% & \text { NMR Yield: } 9 \%\end{array}$
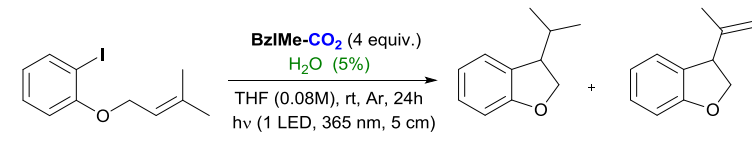

10 Conv: $10 \%$
NMR Yield: $6 \%$ NMR Yield: $20 \%$

Scheme 7. Intramolecular aryl radical additions on alkenes.

Our strategy of in situ generation of a powerful OED from an air-stable precursor also affords the first example of OEDpromoted intermolecular additions of aryl radicals to alkenes (Scheme 8). The aryl radical resulting from the complete reduction of $\mathbf{1 2}$ was added to the external position of the diphenylethylene 13 to obtain the 1,2-diphenylethylbenzene derivative 14 in $36 \%$ yield. The moderate yield probably accounted from the competitive formation of volatile chlorobenzene (15) upon HAT to the aryl radical. The $\alpha$ substituted pyrrole derivative $\mathbf{1 7}$ was obtained in excellent yield through intermolecular addition of the aryl radical of $\mathbf{1 2}$ on the pyrrole 16. Rearomatization of the pyrrole moiety of $\mathbf{1 7}$ probably occurs through radical coupling of the alkyl radical with the radical cation DiBzIMe ${ }^{\bullet+}$, followed by elimination of the resulting benzimidazolium leaving group. ${ }^{32}$

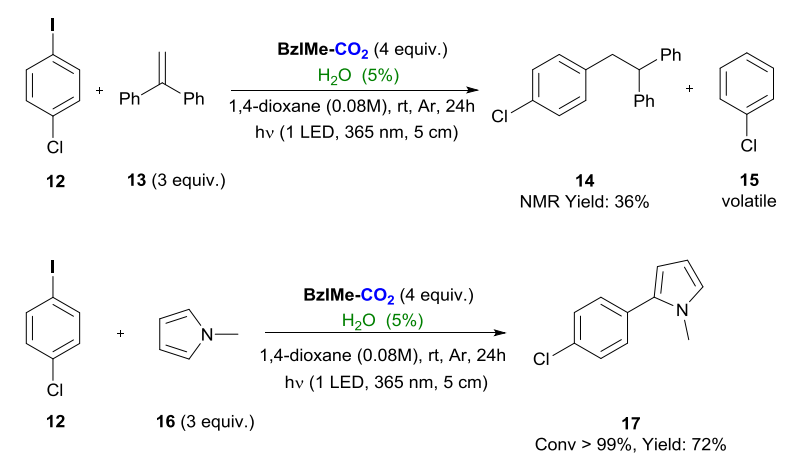

Scheme 8. Intermolecular aryl radical additions on alkenes.

\section{Conclusions}

In conclusion, we demonstrated that water can enhance the decarboxylation of air-stable imidazolium and benzimidazolium carboxylate adducts and thus allow the in situ generation of strong organic electron donors at room temperature. Photo-excited di-1,3-dimethylbenzimidazolin-2ylidene DiBzIMe then promotes the efficient single-electron transfer reduction of sulfonamide and aryl halides. The resulting aryl radicals are then engaged in intramolecular and intermolecular additions to alkenes. A thorough mechanistic study supports the activation pathway and the in-situ formation of the organic electron donor. The multiple strategies that we developed for the activation of $\mathrm{N}$ heterocyclic carboxylate adducts (thermal-, water- or UVactivation) ensure their practicality and should foster their use as air-stable precursors of powerful organic electron donors in radical chemistry.

\section{Conflicts of interest}

There are no conflicts to declare.

\section{Acknowledgements}

The Agence Nationale de la Recherche is gratefully acknowledged for the JCJC ANR grant "iPOD" (17-CE07000101). Aix Marseille Université (AMU) and the Centre National de la Recherche Scientifique (CNRS) are also acknowledged for financial support. GT thanks the Ministère de l'Enseignement supérieur et de la Recherche for his Ph.D. grant. YZ thanks the China Scholarship Council for his Ph.D. grant. We thank Dr. Vincent Remusat for NMR analyses and the Spectropole (Fédération des Sciences Chimiques de Marseille) for spectroscopic analyses.

\section{Notes and references}

1 (a) A. Houmam, Electron Transfer Initiated Reactions: Bond Formation and Bond Dissociation, Chem. Rev., 2008, 108, 2180; (b) G. J. Rowlands, Radicals in organic synthesis. Part 1, Tetrahedron, 2009, 65, 8603; (c) G. J. Rowlands, Radicals in organic synthesis: Part 2, Tetrahedron, 2010, 66, 1593; (d) A. Gansäuer and S. Hildebrandt, in Free-Radical Synthesis and Functionalization of Heterocycles. Topics in Heterocyclic Chemistry, ed. Y. Landais, Springer, Cham, 2017, 54, 253.

2 (a) C. K. Prier, D. A. Rankic and D. W. C. MacMillan, Visible Light Photoredox Catalysis with Transition Metal Complexes: Applications in Organic Synthesis, Chem. Rev., 2013, 113, 5322; (b) M. H. Shaw, J. Twilton and D. W. C. MacMillan, Photoredox Catalysis in Organic Chemistry, J. Org. Chem., 2016, 81, 6898; (c) I. B. Perry, T. F. Brewer, P. J. Sarver, D. M. Schultz, D. A. DiRocco and D. W. C. MacMillan, Direct arylation of strong aliphatic $\mathrm{C}-\mathrm{H}$ bonds, Nature, 2018, 560, 71; (d) R. C. McAtee, E. J. McClain and C. R. J. Stephenson, Illuminating Photoredox Catalysis, Trend in chemistry, Review Special Issue: Big questions in chemistry, 2019, 1, 111.

3 (a) D. A. Nicewicz and T. M. Nguyen, Recent Applications of Organic Dyes as Photoredox Catalysts in Organic Synthesis, ACS Catal., 2014, 4, 355; (b) I. Ghosh, T. Ghosh, J. I. Bardagi and B. König, Reduction of aryl halides by consecutive visible 
light-induced electron transfer processes, Science, 2014, 346, 725; (c) N. A. Romero and D. A. Nicewicz, Organic Photoredox Catalysis, Chem. Rev., 2016, 116, 10075; (d) I. A. MacKenzie, L. Wang, N. P. R. Onuska, O. F. Williams, K. Begam, A. M. Moran, B. D. Dunietz and D. A. Nicewicz, Discovery and characterization of an acridine radical photoreductant Nature, 2020, 580, 76.

4 Murphy and Hasegawa recently reported catalytic versions using the free radical derivatives of aryl-benzimidazolines or dihydrobenzimidazoles as SET-reducing agents: (a) S. Rohrbach, R. S. Shah, T. Tuttle and J. A. Murphy, Neutra Organic Super Electron Donors Made Catalytic, Angew. Chem. Int. Ed., 2019, 58, 11454; (b) E. Hasegawa, T. Tanaka, N. Izumiya, T. Kiuchi, Y. Ooe, H. Iwamoto, S. Takizawa and S. Murata, Protocol for Visible-Light-Promoted Desulfonylation Reactions Utilizing Catalytic Benzimidazolium Aryloxide Betaines and Stoichiometric Hydride Donor Reagents, J. Org. Chem., 2020, 85, 4344 .

5 For reviews, see (a) J. A. Murphy, in Encyclopedia of Radicals in Chemistry, Biology and Materials, ed. C. Chatgilialoglu and A. Studer, WILEY-VCH, Weinheim, 2012, 29, 817; (b) S. Zhou, H. Farwaha and J. A. Murphy, The Development of Organic Super Electron Donors, Chimia, 2012, 66, 418; (c) J. Broggi, T. Terme and P. Vanelle, Organic Electron Donors as Powerful Single-Electron Reducing Agents in Organic Synthesis, Angew. Chem. Int. Ed., 2014, 53, 384; (d) J. A. Murphy, Discovery and Development of Organic Super-ElectronDonors, J. Org. Chem., 2014, 79, 3731; (e) E. Doni and J. A Murphy, Evolution of neutral organic super-electron-donors and their applications, Chem. Commun., 2014, 50, 6073; $(f) \mathrm{Y}$ Zhao and J. Broggi, $N, N, N^{\prime}, N^{\prime}$-Tetramethyl-7,8-Dihydro-6H-Dipyrido

$\left[1,2-\alpha ; 2^{\prime}, 1^{\prime}-c\right][1,4]$ diazepine-2,12-diamine, in Encyclopedia of Reagents for Organic Synthesis, WILEY, 2019.

6 (a) C. S. Sevov, R. E. M. Brooner, E. Chénard, R. S. Assary, J. S. Moore, J. Rodríguez-López and M. S. Sanford, Evolutionary Design of Low Molecular Weight Organic Anolyte Materials for Applications in Nonaqueous Redox Flow Batteries, J. Am Chem. Soc., 2015, 137, 14465; (b) J. Broggi, M. Rollet, J. L. Clément, G. Canard, T. Terme, D. Gigmes and P. Vanelle, Polymerization Initiated by Organic Electron Donors, Angew. Chem. Int. Ed., 2016, 55, 5994; (c) R. Rayala, A. GiuglioTonolo, J. Broggi, T. Terme, P. Vanelle, P. Theard, M. Médebielle and S. F. Wnuk, Studies toward the oxidative and reductive activation of $\mathrm{C}$-S bonds in 2'-S-aryl-2'-thiouridine derivatives, Tetrahedron, 2016, 72, 1969; (d) M. Rueping, $\mathrm{P}$. Nikolaienko, Y. Lebedev and A. Adams, Metal-free reduction of the greenhouse gas sulfur hexafluoride, formation of $\mathrm{SF}_{5}$ containing ion pairs and the application in fluorinations, Green Chem., 2017, 19, 2571; (e) M. Li, S. Berritt, L. Matuszewski, G. Deng, A. Pascual-Escudero, G. B. Panetti, M. Poznik, X. Yang, J. J. Chruma and P. J. Walsh, TransitionMetal-Free Radical $\mathrm{C}\left(s \mathrm{~s}^{3}\right)-\mathrm{C}\left(\mathrm{sp}^{2}\right)$ and $\mathrm{C}\left(\mathrm{sp}^{3}\right)-\mathrm{C}\left(\mathrm{sp}^{3}\right)$ Coupling Enabled by 2-Azaallyls as Super-Electron-Donors and Coupling-Partners, J. Am. Chem. Soc., 2017, 139, 16327; (f) W. Shu, A. Garcia-Dominguez, M. T. Quiros, R. Mondal, D. J. Cardenas and C. Nevado, Ni-Catalyzed Reductive Dicarbofunctionalization of Nonactivated Alkenes: Scope and Mechanistic Insights, J. Am. Chem. Soc., 2019, 141, 13812 (g) G. Nocera and J. A. Murphy, Ground State Cross-Coupling of Haloarenes with Arenes Initiated by Organic Electron Donors, Formed in situ: An Overview, Synthesis, 2020, 52, 327.

7 (a) P. I. Jolly, N. Fleary-Roberts, S. O'Sullivan, E. Doni, S. Zhou and J. A. Murphy, Reactions of triflate esters and triflamides with an organic neutral super-electron-donor, Org. Biomol. Chem., 2012, 10, 5807; (b) H. S. Farwaha, G. Bucher and J. A Murphy, A novel neutral organic electron donor with record half-wave potential, Org. Biomol. Chem., 2013, 11, 8073; (c) C. Spitz, A. Lin, T. Terme and P. Vanelle, Mild and Metal-Free Diastereoselective Synthesis of $\mathrm{N}$-tert-Butanesulfinylamines by Using Tetrakis(dimethylamino)ethylene, Synthesis, 2014, 46, 3229; (d) S. S. Hanson, N. A. Richard and C. A. Dyker, Powerful Bispyridinylidene Organic Reducing Agents with Iminophosphorano $p$-Donor Substituents, Chem. Eur. J., 2015, 21, 8052; (e) S. S. Hanson, E. Doni, K. T. Traboulsee, G. Coulthard, J. A. Murphy and C. A. Dyker, Pushing the Limits of Neutral Organic Electron Donors: A Tetra(iminophosphorano)-Substituted Bispyridinylidene, Angew. Chem. Int. Ed., 2015, 54, 11236; (f) C. Spitz, T. Terme and P. Vanelle, Mild and Metal-Free Regioselective 1,2Addition of Carbon Nucleophiles to $\alpha, \beta$-Unsaturated Imines, Synlett, 2016, 27, 301

8 (a) E. Cahard, F. Schoenebeck, J. Garnier, S. P. Y. Cutulic, S. Zhou and J. A. Murphy, Electron Transfer to Benzenes by Photoactivated Neutral Organic Electron Donor Molecules, Angew. Chem. Int. Ed., 2012, 51, 3673; (b) E. Doni, S. O'Sullivan and J. A. Murphy, Metal-Free Reductive Cleavage of Benzylic Esters and Ethers: Fragmentations Result from Single and Double Electron Transfers, Angew. Chem. Int. Ed., 2013, 52, 2239; (c) E. Doni, B. Mondal, S. O'Sullivan, T. Tuttle and J. A. Murphy, Overturning Established Chemoselectivities: Selective Reduction of Arenes over Malonates and Cyanoacetates by Photoactivated Organic Electron Donors, J. Am. Chem. Soc., 2013, 135, 10934; (d) S. O'Sullivan, E. Doni, T. Tuttle and J. A. Murphy, Metal-Free Reductive Cleavage of $\mathrm{C}-\mathrm{N}$ and $\mathrm{S}-\mathrm{N}$ Bonds by Photoactivated Electron Transfer from a Neutral Organic Donor, Angew. Chem. Int. Ed., 2014, 53, 474.

9 (a) T. A. Taton and P. Chen, A Stable Tetraazafulvalene, Angew. Chem., Int. Ed. Engl., 1996, 35, 1011; (b) J. A. Murphy, J. Garnier, S. R. Park, F. Schoenebeck, S. Zhou and A. T. Turner, Super-Electron Donors: Bis-pyridinylidene Formation by Base Treatment of Pyridinium Salts, Org. Lett., $2008,10,1227$.

10 P. I. Jolly, S. Zhou, D. W. Thomson, J. Garnier, J. A. Parkinson, T. Tuttle and J. A. Murphy, Imidazole-derived carbenes and their elusive tetraazafulvalene dimers, Chem. Sci., 2012, 3, 1675.

11 (a) W. Carpenter and E. M. Bens, The Identification of some of the oxidation products of tetrakis(dimethylamino)ethylene, Tetrahedron, 1970, 26, 59; (b) Z. Shi and R. P. Thummel, Bridged Bibenzimidazolium Salts and Their Conversion to Ureaphanes, Tetrahedron Lett., 1994, 35, 33; (c) D. M. Khramov, A. J. Boydston and C. W. Bielawski, Synthesis and Study of Janus Bis(carbene)s and Their Transition-Metal Complexes, Angew. Chem. Int. Ed., 2006, 45, 6186; (d) J. W. Kamplain, V. M. Lynch and C. W. Bielawski, Synthesis and Study of Differentially Substituted Dibenzotetraazafulvalenes, Org. Lett., 2007, 9, 5401; (e) M. F. Lappert, S. Álvarez, G. Aullón, R. Fandos, A. Otero, A. Rodríguez and S. Rojas, P. Terreros, Reactivity of a SuperElectron-Rich Olefin Derived from Cyclam, Eur. J. Inorg. Chem., 2009, 13, 1851.

12 (a) J. A. Murphy, T. A. Khan, S. Zhou, D. W. Thomson and M. Mahesh, Highly Efficient Reduction of Unactivated Aryl and Alkyl lodides by Ground-State Neutral Organic Electron Donor, Angew. Chem. Int. Ed., 2005, 44, 1356; (b) J. Garnier, J. A. Murphy, S. Zhou and A. T. Turner, One-Pot Reduction of Aryl lodides Using 4-DMAP Methiodide Salt, Synlett., 2008, 2127.

13 G. Tintori, P. Nabokoff, R. Buhaibeh, D. Bergé-Lefranc, R. Redon, J. Broggi and P. Vanelle, Base-Free Generation of Organic Electron Donors from Air-Stable Precursors, Angew. Chem. Int. Ed., 2018, 57, 3148. 
14 R. Lindner, M. L. Lejkowski, S. Lavy, P. DegImann, K. T. Wiss, S. Zarbakhsh, L. Meyer and M. Limbach, Ring-Opening Polymerization and Copolymerization of Propylene Oxide Catalyzed by $\mathrm{N}$-Heterocyclic Carbenes, ChemCatChem, 2014, 6, 618.

15 L. H. Finger, J. Guschlbauer, K. Harms and J. Sundermeyer, NHeterocyclic Olefin-Carbon Dioxide and -Sulfur Dioxide Adducts: Structures and Interesting Reactivity Patterns, Chem. Eur. J., 2016, 22, 16292.

16 Denk et al. predicted a dative character for the long C-S bond of NHC- $\mathrm{SO}_{2}$ adducts and a bond dissociation energies $<20$ kcal.mol ${ }^{-1}$. M. K. Denk, K. Hatano and A. J. Lough, Synthesis and Characterization of a Carbene $\cdot \mathrm{SO}_{2}$ Adduct - New Insights into the Structure and Bonding of Thiourea S,S-Dioxides, Eur. J. Inorg. Chem., 2003, 224.

17 Similarly, we had already demonstrated that the decarboxylation temperature of the solid DMAP-Me- $\mathbf{C O}_{2}$ $\left(181^{\circ} \mathrm{C}\right)$ was overestimated compared to the temperature of activation observed in solution $\left(120^{\circ} \mathrm{C}\right) .^{13}$ This was attributed to the well-organized arrangement of the solid DMAP-Me$\mathrm{CO}_{2}$ favouring strong hydrogen-bond interactions.

18 B. R. Van Ausdall, J. L. Glass, K. M. Wiggins, A. M. Aarif and J. Louie, A Systematic Investigation of Factors Influencing the Decarboxylation of Imidazolium Carboxylates, J. Org. Chem. 2009, 74, 7935.

19 (a) D. M. Denning and D. E. Falvey, Solvent-Dependent Decarboxylation of 1,3-Dimethylimdazolium-2-Carboxylate, J. Org. Chem., 2014, 79, 4293; (b) D. M. Denning, M. D. Thum and D. E. Falvey, Photochemical Reduction of $\mathrm{CO}_{2}$ Using 1,3Dimethylimidazolylidene, Org. Lett., 2015, 17, 4152; (c) D. M. Denning and D. E. Falvey, Substituent and Solvent Effects on the Stability of $\mathrm{N}$ - Heterocyclic Carbene Complexes with $\mathrm{CO}_{2}$, J. Org. Chem., 2017, 82, 1552.

20 All reactions were carried out in the presence of two cooling fans to avoid a rise of temperature due to UV-irradiations. The temperature media did not exceed $30^{\circ} \mathrm{C}$.

21 Considering the strong constraint of the ${ }^{t} \mathrm{Bu}$ groups and the inclination of imidazolium series to form carbenes rather than enamine dimers in the Wanzlick equilibrium, ${ }^{10}$ we cannot totally exclude the sole formation of $I^{t} \mathrm{Bu}$ carbene in this case. Under UV-irradiations, $I^{t} \mathbf{B u}$ could be the active electron donor, transferring one electron to the substrate 1 a.

22 Water was not necessary for the reduction of 1a using two equivalents of DiBzIMe under UV-irradiations. But water was left to keep the reaction conditions as close as possible to the ones used with BzIMe- $\mathrm{CO}_{2}$.

23 Note that no reduction was observed using BzIMeO as reducer source (Table 3, Entry 9).

24 (a) D. M. Lemal, R. A. Lovald and K. I. Kawano, Tetraaminoethylenes. The Question of Dissociation, J. Am. Chem. Soc., 1964, 86, 2518; (b) N. Wiberg, Tetraaminoethylenes as Strong Electron Donors, Angew. Chem. Int. Ed. Engl., 1968, 7, 766; (c) R. W. Hoffmann, Reactions of Electron-Rich Olefins, Angew. Chem. Int. Ed. Engl., 1968, 7, 754-765.

25 J. Messelberger, A. Grünwald, S. J. Goodner, F. Zeilinger, P. Pinter, M. E. Miehlich, F. W. Heinemann, M. M. Hansmann and D. Munz, Aromaticity and sterics control whether a cationic olefin radical is resistant to disproportionation, Chem. Sci., 2020, 11, 4138.

26 T. P. Vaid and M. S. Sanford, An organic super-electrondonor as a high energy density negative electrolyte for nonaqueous flow batteries, Chem. Commun., 2019, 55 11037.

27 B. Gorodetsky, T. Ramnial, N. R. Branda and J. A. C. Clyburne, Electrochemical reduction of an imidazolium cation: a convenient preparation of imidazol-2-ylidenes and their observation in an ionic Liquid, Chem. Commun., 2004, 1972.

28 (a) Y. Liu, P. E. Lindner and D. M. Lemal, Thermodynamics of

Diaminocarbene-Tetraaminoethylene Equilibrium, J. Am. Chem. Soc., 1999, 121, 10626; (b) V. P. W. Böhm and W. A. Herrmann, The "Wanzlick Equilibrium", Angew. Chem. Int. Ed., 2000, 39, 4036.

29 (a) Y. Yoshimi, T. Itou and M. Hatanaka, Decarboxylative reduction of free aliphatic carboxylic acids by photogenerated cation radical, Chem. Commun., 2007, 5244; (b) Y. Yoshimi, M. Masuda, T. Mizunashi, K. Nishikawa, K. Maeda, N. Koshida, T. Itou, T. Morita and M. Hatanaka, Interand Intramolecular Addition Reactions of Electron-Deficient Alkenes with Alkyl Radicals, Generated by SETPhotochemical Decarboxylation of Carboxylic Acids, Serve as a Mild and Efficient Method for the Preparation of $\gamma$-Amino Acids and Macrocyclic Lactones, Org. Lett., 2009, 11, 4652; (c) J. Xuan, Z. Zhang and W. Xiao, Visible-Light-Induced Decarboxylative Functionalization of Carboxylic Acids and Their Derivatives, Angew. Chem. Int. Ed., 2015, 54, 15632; (d) L. Candish, M. Freitag, T. Gensch and F. Glorius, Mild, visible light-mediated decarboxylation of aryl carboxylic acids to access aryl radicals, Chem. Sci., 2017, 8, 3618; (e) L. Cao and Y. Wang, Photocatalysis of viologens for photoinitiated polymerization using carboxylic acid as electron donors, J. Photochem. Photobio. A: Chemistry, 2017, 333, 63; (f) C. Shu, R. S. Mega, B. J. Andreassen, A. Noble and V. K. Aggarwal, Synthesis of Functionalized Cyclopropanes from Carboxylic Acids by a Radical Addition-Polar Cyclization Cascade, Angew. Chem. Int. Ed., 2018, 57, 15430.

30 For acid-catalysed dimerization of carbene where the azolium salt plays the role of the acid, see: $(a) \mathrm{R}$. W. Alder, M. E. Blake, L. Chaker, J. N. Harvey, F. Paolini and J. Schütz, When and How Do Diaminocarbenes Dimerize?, Angew. Chem. Int. Ed., 2004, 43, 5896; (b) D. C. Graham, K. J. Cavell and B. F. Yates, Dimerization mechanisms of heterocyclic carbenes, J. Phys. Org. Chem., 2005, 18, 298.

31 D. P. Curran and M. J. Totleben, The Samarium Grignard Reaction. In Situ Formation and Reactions of Primary and Secondary Alkylsamarium(III) Reagents, J. Am. Chem. Soc., 1992, 114, 6050

32 (a) J. A. Murphy, F. Schoenebeck, N. J. Findlay, D. W. Thomson, S. Zhou and J. Garnier, One-Carbon Extrusion from a Tetraazafulvalene. Isolation of Aldehydes and a Study of Their Origin, J. Am. Chem. Soc., 2009, 131, 6475; (b) R. Sword, L. A. Baldwin and J. A. Murphy, Fragmentations observed in the reactions of $\alpha$-methoxy- $\gamma$-alkoxyalkyl iodide substrates with super-electron-donors derived from 4-DMAP and $\mathrm{N}$-methylbenzimidazole, Org. Biomol. Chem., 2011, 9, 3560. 